\title{
Very low specific contact resistance measurements made on a highly p-type doped 4H-SiC layer selectively grown by vapor-liquid- solid transport
}

N. Thierry-Jebali, A. Vo-Ha, D. Carole, M. Lazar, G. Ferro, D. Planson, Anne Henry and P. Brosselard

\section{Linköping University Post Print}

\section{Tweet}

N.B.: When citing this work, cite the original article.

Original Publication:

N. Thierry-Jebali, A. Vo-Ha, D. Carole, M. Lazar, G. Ferro, D. Planson, Anne Henry and P. Brosselard, Very low specific contact resistance measurements made on a highly p-type doped 4H-SiC layer selectively grown by vapor-liquid-solid transport, 2013, Applied Physics Letters, (102), 21, 212108.

http://dx.doi.org/10.1063/1.4809570

Copyright: American Institute of Physics (AIP) http://www.aip.org/

Postprint available at: Linköping University Electronic Press http://urn.kb.se/resolve?urn=urn:nbn:se:liu:diva-96135 


\title{
Very low specific contact resistance measurements made on a highly p-type doped $4 \mathrm{H}-\mathrm{SiC}$ layer selectively grown by vapor-liquid-solid transport
}

\author{
N. Thierry-Jebali, ${ }^{1}{ }^{1, a)}$ A. Vo-Ha, ${ }^{2}$ D. Carole, ${ }^{2}$ M. Lazar, ${ }^{1}$ G. Ferro, ${ }^{2}$ D. Planson, ${ }^{1}$ A. Henry, ${ }^{3}$ \\ and P. Brosselard $\left.{ }^{1, b}\right)$ \\ ${ }^{1}$ Université de Lyon, INSA de Lyon, Laboratoire Ampère, CNRS UMR 5005, 21 av. Jean Capelle \\ F69621 Villeurbanne, France \\ ${ }^{2}$ Université de Lyon, Université Lyon-1, Laboratoire des Multimatriaux et Interfaces, CNRS UMR 5615, \\ 22 av. Gaston Berger, F69622 Villeurbanne, France \\ ${ }^{3}$ Department of Physics, Chemistry and Biology, Linköping University, SE-581 83 Linköping, Sweden
}

(Received 29 January 2013; accepted 17 May 2013; published online 31 May 2013)

\begin{abstract}
This work reports on the performances of ohmic contacts fabricated on highly p-type doped $4 \mathrm{H}-\mathrm{SiC}$ epitaxial layer selectively grown by vapor-liquid-solid transport. Due to the very high doping level obtained, the contacts have an ohmic behavior even without any annealing process. Upon variation of annealing temperatures, it was shown that both 500 and $800{ }^{\circ} \mathrm{C}$ annealing temperature lead to a minimum value of the Specific Contact Resistance (SCR) down to $1.3 \times 10^{-6} \Omega \cdot \mathrm{cm}^{2}$. However, a large variation of the minimum SCR values has been observed (up to $4 \times 10^{-4} \Omega \cdot \mathrm{cm}^{2}$ ). Possible sources of this fluctuation have been also discussed in this paper. (C) 2013 AIP Publishing LLC. [http://dx.doi.org/10.1063/1.4809570]
\end{abstract}

Wide band gap semiconductors such as $\mathrm{SiC}, \mathrm{GaN}$, or diamond received much attention in order to design and fabricate the forthcoming power electronics devices. Indeed, their exceptional properties like a high band gap, a high critical electric field, and a high thermal conductivity can lead to significant improvements in terms of high temperature, high frequency, and high power operations and theoretically conduct to an outstanding decrease of power losses.

The improvement of the $4 \mathrm{H}-\mathrm{SiC}$ bulk and epilayer material quality led to the development of unipolar devices commercially available such as Schottky rectifiers, Junction Field Effect Transistors (JFETs), and Metal Oxide Semiconductor Field Effect Transistors (MOSFETs). However, some technological barriers still persist. One of them is the formation of a good ohmic contact on p-type $4 \mathrm{H}-\mathrm{SiC}$, which is an important building block for the performance of electronics devices and which has not been fully validated yet. ${ }^{1}$

The difficulties are numerous. First, p-type dopant impurities have high ionization energies. For example, the ionization energy for $\mathrm{Al}$, which is the commonly used p-type dopant element for $4 \mathrm{H}-\mathrm{SiC}$, is $190 \mathrm{meV}{ }^{2,3}$ Therefore, finding a metal with a sufficient low Schottky barrier height (SBH) is very difficult. Even though many metals have been investigated for obtaining an ohmic contact on p-type hexagonal $\mathrm{SiC},{ }^{4} \mathrm{Ti} / \mathrm{Al}$ based metallizations have given the best results in terms of specific contact resistance (SCR) when annealed at high temperature $\left(>800^{\circ} \mathrm{C}\right) .{ }^{1}$ On epitaxial p-type layer, one can expect SCR ranging in the mid $10^{-5} \Omega \cdot \mathrm{cm}^{2},{ }^{1,5}$ which is acceptable for most of applications in power electronics but still needs to be improve for higher current capabilities. Theoretically, by increasing locally the doping level close to the contact, one is expecting a decrease of the SCR.

Currently, $\mathrm{Al}$ ion implantation is the common technique to perform localized $\mathrm{p}^{+}$doping with, nevertheless, significant

\footnotetext{
a) nicolas.thierry-jebali@insa-lyon.fr

b) pierre.brosselard@insa-lyon.fr
}

drawbacks. First, the high energy ions degrade the crystal quality and a high temperature annealing, up to $1700^{\circ} \mathrm{C}$, is required to both partially activate the $\mathrm{Al}$ elements and tentatively restore the crystal quality. ${ }^{6}$ Moreover, to increase minority carrier lifetime for bipolar devices, additional steps including either oxidation or $\mathrm{C}$ implantation and relatively low temperature annealing have been proposed. ${ }^{7,8}$ However, if the temperature is higher than $1700^{\circ} \mathrm{C}$ a degradation of the minority carrier lifetime is observed together with an increase of the concentration of the $\mathrm{z}_{1 / 2}$ defect center. ${ }^{7,8} \mathrm{In}$ practice, obtaining a high p-type doping level with acceptable defects densities has not been possible yet and the SCR values on these implanted layers range in the mid $10^{-4} \Omega \cdot \mathrm{cm}^{2}{ }^{1}$. Second, the depth of the p-type implanted areas is limited to a few hundreds of $\mathrm{nm}$ for standard ion implanter energy $(<200 \mathrm{keV})$. As a consequence of these drawbacks, Al implantation process has been mainly banished for the $4 \mathrm{H}-\mathrm{SiC}$ JFETs fabrication at the benefit of epitaxial layer regrowth.

Recently, SiC Selective Epitaxial Growth (SEG) by Vapour-Liquid-Solid (VLS) transport in a buried structure appears as a promising solution to create deep, highly p-typed doped, and high crystal quality areas. Such SEGVLS growth has been demonstrated on both large and small circular area and square-shaped structure buried down to $1 \mu \mathrm{m} .{ }^{9,10}$ The $\mathrm{Al}$ concentration levels of these structures have been measured by Secondary Ion Mass Spectrometry (SIMS) higher than $N_{a}=10^{20} \mathrm{~cm}^{-3} \cdot{ }^{11,12}$ Moreover, a high quality $\mathrm{p}^{+}(\mathrm{VLS})-\mathrm{n}$ junction can be achieved by using this technique, which offers new prospects for the achievement of new power electronics devices, including deeply buried peripheral protection zones such as guard rings or Junction Barrier Schottky (JBS) structures. ${ }^{13}$

This paper presents a study of ohmic contacts properties realized on $p^{+}-$type $4 \mathrm{H}-\mathrm{SiC}$ buried SEG-VLS layer.

The performance of ohmic contacts has been studied by the extraction of the SCR values, thanks to the Transfer 
Length Method (TLM). Fabrication of the TLM structures was carried as follows. A $15 \mu \mathrm{m} \mathrm{n} \mathrm{n}^{-}$layer doped at $5 \times 10^{15} \mathrm{~cm}^{-3}$ has been grown on a $8^{\circ}$-off $4 \mathrm{H}$-SiC substrate in a hot-wall chemical vapor deposition (CVD) reactor. Then the TLM patterns area has been defined by etching a $1 \mu \mathrm{m}$ depth bowl-shape structure into the $\mathrm{n}^{-}$layer by Reactive Ion Etching. This area has been filled by a $\operatorname{Si}(1.1 \mu \mathrm{m}) / \mathrm{Al}(1.5 \mu \mathrm{m})$ bilayer deposited by e-beam. The VLS growth has been performed at $1100^{\circ} \mathrm{C}$ during 5 min with $\mathrm{Ar}$ as carrier gas and propane as carbon source. ${ }^{13}$ Micro-Raman spectrometry, electron backscatter diffraction phase mapping and transmission electron microscopy observation (not shown here) did not display any evidence of $3 \mathrm{C}$ polytype inclusion. The structure of the TLM pattern is reported in Fig. 1. Due to the step bunched growth mode, we observe that the VLS layer surface is quite rough. ${ }^{9,10}$

The ohmic contact was formed by depositing $\mathrm{Ni}(10 \mathrm{~nm}) /$ $\mathrm{Ti}(40 \mathrm{~nm}) / \mathrm{Al}(240 \mathrm{~nm}) / \mathrm{Ni}(10 \mathrm{~nm})$ metallic stacks by e-beam. Current-Voltage (I-V) measurements have been done on TLM patterns "as-deposited." Finally the sample has been recursively annealed from 200 to $800^{\circ} \mathrm{C}$, with a $100^{\circ} \mathrm{C}$ step, and I-V measurements have been recorded for each temperature.

Fig. 2(a) displays the I-V measurements as a function of space between pads (d1 to d5) of a typical "as-deposited" TLM pattern. Surprisingly, I-V behaviors are linear and prove that the contact is already ohmic. This result can be explained by the high doping level of the SEG-VLS layer, which favors the tunnel effect, even for a contact with a high $\mathrm{SBH}$ and tends to demonstrate that most of $\mathrm{Al}$ elements are electrically activated in the $4 \mathrm{H}-\mathrm{SiC}$ epilayer. To the best of our knowledge, performing an as-deposited ohmic contact on p-type $4 \mathrm{H}-\mathrm{SiC}$ has never been demonstrated in the past.

The variation of the SCR values extracted from the $R(d)$ characteristics (Fig. 2(b)) is quite high and those values ranges from $5 \times 10^{-4} \Omega \cdot \mathrm{cm}^{2}$ to $7 \times 10^{-3} \Omega \cdot \mathrm{cm}^{2}$.

Fig. 3 reports the evolution of the SCR values as a function of the annealing temperature of six typical TLM patterns called "Field" in the figure and distributed on the sample. Some patterns have been characterized prior to the annealing step until the higher annealing temperature, while others started to be characterized at different annealing temperatures in order to exclude a possible influence of the electrical measurements on the evolution of the SCR value with the annealing temperature.

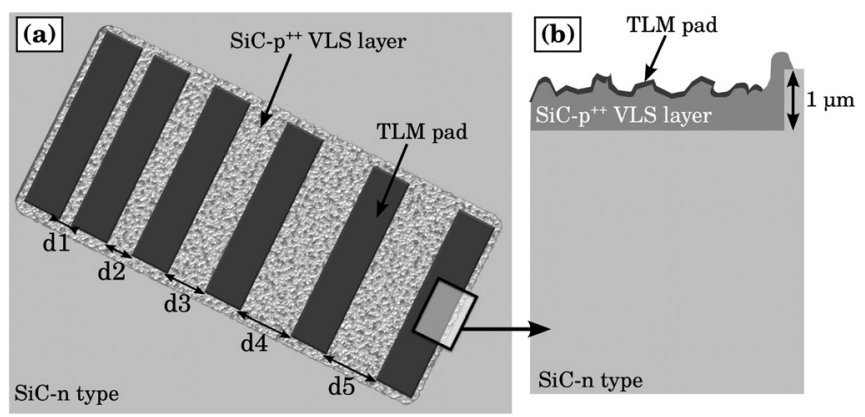

FIG. 1. (a) Schematic view of processed TLM patterns. The area of each TLM pad is $310 \times 110 \mu \mathrm{m}^{2}$ and the spacing $d_{i}=[10,20,30,40,50] \mu \mathrm{m}$; (b) cross section of the structure of the TLM pattern close to a contact pad.
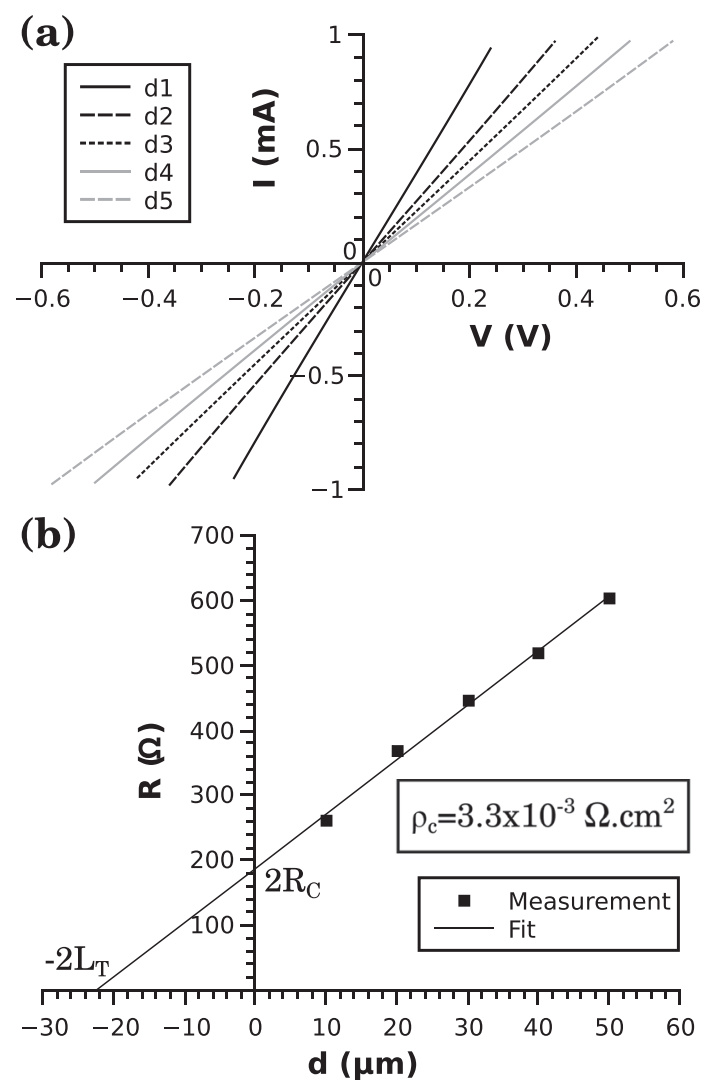

FIG. 2. (a) I-V measurements as a function of space between pads of a typical "as deposited" TLM pattern; (b) R-d behaviour extracted from I-V measurements.

One can see that the evolution of the SCR with the annealing temperature is the same for all tested patterns. Fig. 3 demonstrates that both 500 and $800^{\circ} \mathrm{C}$ annealing temperature lead to a minimum SCR value. Thus, SCR decrease significantly from 200 to $500^{\circ} \mathrm{C}$. Then, the SCR increase to an annealing temperature of $700^{\circ} \mathrm{C}$ and finally decrease at $800^{\circ} \mathrm{C}$.

As already observed for the as-deposited configuration, the variation of the SCR value for a same annealing condition is large and can be higher than two orders of magnitude. For example, the maximum SCR value when annealed

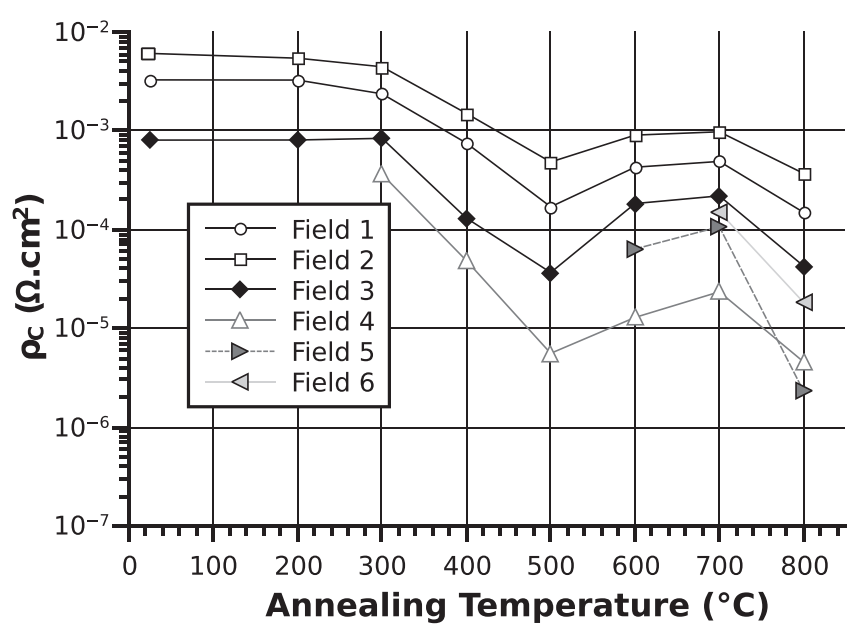

FIG. 3. Evolution of the SCR $\left(\rho_{c}\right)$ as a function of the annealing temperature of six different TLM patterns reported on the sample. 
at $800{ }^{\circ} \mathrm{C}$ is $4 \times 10^{-4} \Omega \cdot \mathrm{cm}^{2}$ when the minimum is $1.3 \times 10^{-6} \Omega \cdot \mathrm{cm}^{2}$. The minimum value is one of the lowest SCR ever reported in the literature on p-type $4 \mathrm{H}-\mathrm{SiC},{ }^{14}$ for the best of our knowledge. This result is promising for the realization of power devices that need a low contact resistance on p-type $4 \mathrm{H}-\mathrm{SiC}$.

Several hypotheses, possibly cumulative, can explain the huge fluctuation of the SCR. First, the doping level at the surface of the VLS layer could be nonhomogeneous. Then, the SBH may also be nonhomogeneous. Indeed, according to the Field Emission (FE) and the Thermionic-Field Emission (TFE) theories, the SCR value mainly depends on the SBH, the doping level of the epilayer, and the temperature. ${ }^{15,16}$

In order to extract the doping level and the $\mathrm{SBH}$, we performed SCR extraction at different measurement temperatures from 300 to $600 \mathrm{~K}$ from four TLM patterns. The evolution of the SCR with the temperature of our sample agrees with the TFE theory and can be written as follows: ${ }^{15,16}$

$$
\begin{aligned}
\rho_{c}= & \frac{k^{2}}{q A^{*} \sqrt{\pi\left(\Phi_{b}+V_{p}\right)} E_{00}} \cosh \left(\frac{E_{00}}{k T}\right) \\
& \times\left[\sqrt{\frac{E_{00}}{k T}}\right] \exp \left(\frac{\Phi+V_{p}}{E_{0}}-\frac{V_{p}}{k T}\right),
\end{aligned}
$$

where

$$
E_{0}=E_{00} \operatorname{coth}\left(\frac{E_{00}}{k T}\right)
$$

and

$$
E_{00}=\frac{q h}{4 \pi} \sqrt{\frac{N_{a}}{m^{*} \epsilon}},
$$

where $k$ is the Boltzmann constant, $h$ is the Planck constant, $A^{*}$ is the $4 \mathrm{H}-\mathrm{SiC}$ Richardson constant, $m^{*}$ is the effective mass of the tunneling electron, $\epsilon$ is the dielectric constant of the $4 \mathrm{H}-\mathrm{SiC}$, and $T$ is the temperature. $V_{p}$ is the energy difference between the valence-band and the Fermi level, $\Phi_{b}$ is the

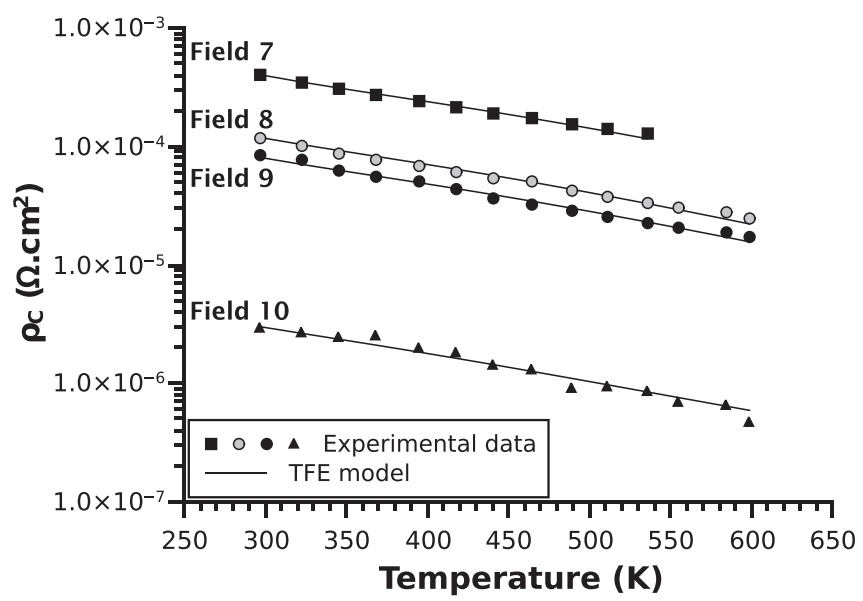

FIG. 4. Evolution of the SCR as a function of the measurement temperature of four different TLM patterns annealed at $800^{\circ} \mathrm{C}$. Experimental data have been fitted with the TFE model. Extracted values of $\Phi_{b}$ and $N_{a}$ are reported on Table I.
TABLE I. Extracted values of $\Phi_{b}$ and $N_{a}$ from $\rho_{c}-T$ characteristics plotted in Fig. 4.

\begin{tabular}{llccr}
\hline \hline Field & $\Phi_{b}(\mathrm{eV})$ & $\begin{array}{c}N_{a} \times 10^{20} \\
\left(\mathrm{~cm}^{-3}\right)\end{array}$ & $\begin{array}{c}\text { VLS layer } \\
\text { thickness }(\mathrm{nm})\end{array}$ & $\begin{array}{r}\rho_{c} @ 25^{\circ} \mathrm{C} \\
\left(\Omega \cdot \mathrm{cm}^{2}\right)\end{array}$ \\
\hline 7 & 1.5 & 2.9 & 620 & $4.1 \times 10^{-4}$ \\
8 & 1.27 & 2.5 & 650 & $1.1 \times 10^{-4}$ \\
9 & 1.23 & 2.5 & 710 & $1 \times 10^{-4}$ \\
10 & 0.735 & 1.7 & 800 & $2.8 \times 10^{-6}$ \\
\hline \hline
\end{tabular}

Schottky barrier height of the contact, and $N_{a}$ is the net carrier concentration of the VLS layer.

Fig. 4 displays the evolution of the measured SCR value with the measurement temperature and their fitted curve with the TFE theory extracted. The extracted values of $\Phi_{b}$ and $N_{a}$ from curves in Fig. 4 are reported in Table I and vary from 0.73 to $1.5 \mathrm{eV}$ for $\Phi_{b}$ and from $1.7 \times 10^{20} \mathrm{~cm}^{-3}$ to $2.9 \times 10^{20} \mathrm{~cm}^{-3}$ for $N_{a}$, respectively. The extracted values of $N_{a}$ confirm the high doping level of the SEG-VLS layer and are in agreement with $\mathrm{Al}$ concentration values measured by SIMS in our previous works. ${ }^{11,12}$ In contrast, extracted values of $\Phi_{b}$ vary significantly even if our highest and lowest SBH can be compared to those reported in the literature. ${ }^{17,18}$ As a consequence, the variation of the SCR is mainly related to a fluctuation of the SBH. Since the SBH is related to the intimate metal/4H-SiC interface, something is happening either during the VLS growth or contact annealing which favors or not the lowering of the SBH. To complete this work, some physical and chemical characterizations and observations of the metal/4H-SiC interface are needed. This is under progress.

In this work, we have studied the ohmic contacts performances fabricated on a buried SEG-VLS layer. Surprisingly, contacts are ohmic "as deposited," which demonstrate the high doping level of the VLS layer. The influence of the annealing temperature on the SCR was also analyzed and demonstrates that both 500 and $800^{\circ} \mathrm{C}$ annealing temperatures lead to an improvement of the SCR down to the mid $10^{-6} \Omega \cdot \mathrm{cm}^{2}$. These results offer new prospects for the realization of JBS rectifiers or higher current capability $\mathrm{PiN}$ diodes.

However, SCR values are inhomogeneous and vary within two orders of magnitude. This variation has been attributed to a large distribution of the SBH of the contact.

In conclusion, since the $\mathrm{SBH}$ is related to the intimate metal/4H-SiC interface, something is happening during the VLS growth which favors or not the lowering of the SBH.

The authors thank the Agence Nationale pour la Recherche, ANR, for its financial support in the framework of the Very High Voltage Devices SiC project (VHVD-SiC, ANR-08-BLAN-0191).

${ }^{1}$ F. Roccaforte, A. Frazzetto, G. Greco, F. Giannazzo, P. Fiorenza, R. L. Nigro, M. Saggio, M. Leszczyski, P. Pristawko, and V. Raineri, Appl. Surf. Sci. 258, 8324 (2012).

${ }^{2}$ Y. Negoro, T. Kimoto, H. Matsunami, F. Schmid, and G. Pensl, J. Appl. Phys. 96, 4916 (2004).

${ }^{3}$ M. Rambach, A. Bauer, and H. Ryssel, Phys. Status Solidi B 245, 1315 (2008). 
${ }^{4}$ F. Roccaforte, F. La Via, and V. Raineri, Int. J. High Speed Electron. Syst. 15, 781 (2005).

${ }^{5}$ F. Laariedh, M. Lazar, P. Cremillieu, J. Leclercq, and D. Planson, in Materials Science Forum (Trans Tech Publ, 2012), Vol. 711, pp. 169-173.

${ }^{6}$ V. Heera, A. Mucklich, C. Dubois, M. Voelskow, and W. Skorupa, J. Appl. Phys. 96, 2841 (2004).

${ }^{7}$ T. Miyazawa and H. Tsuchida, in Materials Science Forum (Trans Tech Publ, 2012), Vol. 717, pp. 81-86.

${ }^{8}$ K. Kawahara, J. Suda, and T. Kimoto, in Materials Science Forum (Trans Tech Publ, 2012), Vol. 717, pp. 241-246.

${ }^{9}$ D. Carole, S. Berckmans, A. Vo-Ha, M. Lazar, D. Tournier, P. Brosselard, V. Soulière, L. Auvray, G. Ferro, and C. Brylinski, in Materials Science Forum (Trans Tech Publ, 2012), Vol. 717, pp. 169-172.

${ }^{10}$ D. Carole, A. Vo-Ha, M. Lazar, N. Thierry-Jebali, D. Tournier, P. Brosselard, A. Thomas, V. Soulière, and G. Ferro, MRS Proc. 1433 (2012).
${ }^{11}$ C. Jacquier, G. Ferro, C. Balloud, M. Zielinski, J. Camassel, E. Polychroniadis, J. Stoemenos, F. Cauwet, and Y. Monteil, in Materials Science Forum (Trans Tech Publ, 2004), Vol. 457, pp. 735-738.

${ }^{12}$ M. Lazar, C. Jacquier, C. Dubois, C. Raynaud, G. Ferro, D. Planson, P. Brosselard, Y. Monteil, and J. Chante, in Materials Science Forum (Trans Tech Publ, 2005), Vol. 483, pp. 633-636.

${ }^{13}$ N. Thierry-Jebali, M. Lazar, A. Vo-Ha, D. Carole, V. Soulière, F. Laariedh, J. Hassan, A. Henry, E. Janzén, and P. Planson, in Materials Science Forum (Trans Tech Publ, 2013), Vol. 740, pp. 911-914.

${ }^{14}$ S. Lee, C. Zetterling, M. Östling, J. Palmquist, and U. Jansson, Microelectron. Eng. 60, 261 (2002).

${ }^{15}$ F. Padovani and R. Stratton, Solid-State Electron. 9, 695 (1966).

${ }^{16}$ A. Yu, Solid-State Electron. 13, 239 (1970).

${ }^{17}$ A. Frazzetto, F. Giannazzo, R. Nigro, V. Raineri, and F. Roccaforte, J. Phys. D: Appl. Phys. 44, 255302 (2011).

${ }^{18}$ M. Gao, S. Tsukimoto, S. Goss, S. Tumakha, T. Onishi, M. Murakami, and L. Brillson, J. Electron. Mater. 36, 277 (2007). 